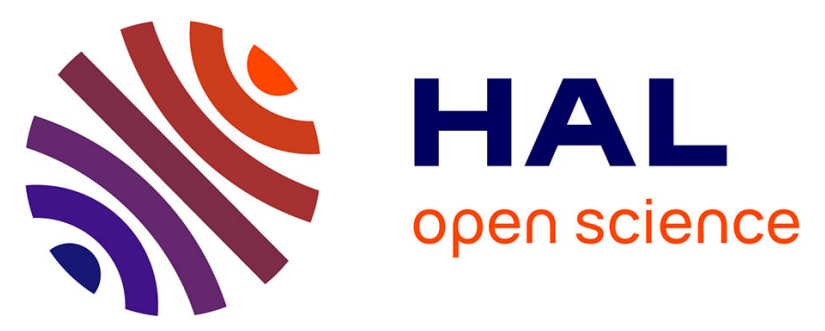

\title{
Validation of plasma amino acid profile using UHPLC-mass spectrometer (QDa) as a screening method in a metabolic disorders reference centre: Performance and accreditation concerns
}

C Bruno, C Veyrat-Durebex, C H Lumbu Lukuntonda, C R Andres, Nicolas Moreau, C Bendavid, C Homedan, F Labarthe, M Tardieu, A Bigot, et al.

\section{To cite this version:}

C Bruno, C Veyrat-Durebex, C H Lumbu Lukuntonda, C R Andres, Nicolas Moreau, et al.. Validation of plasma amino acid profile using UHPLC-mass spectrometer (QDa) as a screening method in a metabolic disorders reference centre: Performance and accreditation concerns. Clinical Biochemistry, 2021, 10.1016/j.clinbiochem.2021.03.004 . hal-03194389

\author{
HAL Id: hal-03194389 \\ https://hal.science/hal-03194389
}

Submitted on 21 Apr 2021

HAL is a multi-disciplinary open access archive for the deposit and dissemination of scientific research documents, whether they are published or not. The documents may come from teaching and research institutions in France or abroad, or from public or private research centers.
L'archive ouverte pluridisciplinaire HAL, est destinée au dépôt et à la diffusion de documents scientifiques de niveau recherche, publiés ou non, émanant des établissements d'enseignement et de recherche français ou étrangers, des laboratoires publics ou privés. 
Validation of plasma amino acid profile using UHPLC-mass spectrometer ( $Q D a)$ as a screening method in a metabolic disorders reference centre: performance and accreditation concerns.

Bruno $C^{1,2,6}$, Veyrat-Durebex $C^{1,2,6}$, LumbuLukuntondaC $H^{1,6}$, Andres $\mathrm{CR}^{1,2,6}$, Moreau $\mathrm{C}^{7}$, Bendavid $\mathrm{C}^{7}, \mathrm{C}$. Homedan ${ }^{8}$, Labarthe $\mathrm{F}^{3,4,6}$, Tardieu $\mathrm{M}^{3,6}$, Bigot $\mathrm{A}^{5,6}$, Maillot $\mathrm{F}^{2,5,6}$, Benz-de Bretagne $\mathrm{I}^{1,2,6}$, Blasco $\mathrm{H}^{1,2,6}$

1-Laboratoire de Biochimie et Biologie Moléculaire, CHRU de Tours, Tours, France

2-Unité INSERM U1253, équipe "neurogénomique et physiopathologie neuronale", Université de Tours, Tours, France

3-Service de Médecine pédiatrique, CHRU de Tours, Tours, France

4-UMR INSERM U 1069 - Nutrition, Croissance et Cancer (N2C), Université de Tours, Tours, France 5-Service de Médecine Interne, CHRU de Tours, Tours, France

6- Centre de référence des maladies héréditaires de métabolisme - filière G2M

7- Laboratoire de biochimie-toxicologie, Hôpital Pontchaillou CHU Rennes, France, Université de Rennes, Inserm, Inra, Institut NuMeCan, CHU Rennes, France

8-Laboratoire de biochimie et génétique, Centre hospitalier universitaire, Angers, France.

*CorrespondingAuthor: Dr Clément Bruno

Laboratoire de Biochimie et Biologie Moléculaire

Hôpital Bretonneau, Bâtiment B2A

2 Boulevard Tonnellé

37044 TOURS.

Tel +3324747 7236

Fax : +33247478613

Email : clement.bruno@univ-tours.fr 
Introduction

Amino acid (AA) analysis in plasma is essential for diagnosis and monitoring of inborn errors of metabolism (IEM). The efficacy of patient management is governed by the rapidity of AA profile availability, along with the robustness of the method. French quality guidelines and progress made in analytical techniques have led biologists to develop AA profile exploration via mass spectrometry (MS).

\section{Objectives}

The aim of this study was to validate an analytical method with a single quadrupole mass spectrometer (MS) and to suggest reference values in regard to French quality and IEM society recommendations.

Design and methods

Plasma samples from patients were deproteinised and derivatised with AccqTag ${ }^{\mathrm{TM}}$ reagent. Analysis was performed by reverse-phase chromatography coupled to QDA detector. We evaluated accuracy, intra-days and inter-days precision and limit of quantification by the $\beta$-expectation tolerance interval method for 27 AA. Method comparison was performed with the standard method (ion exchange chromatography, IEC) on Jeol Aminotac ${ }^{\circledR}$ and to tandem MS. Reference values were established on AA concentrations of the cohort of patients who had no IEM.

Results

Our method allowed the separations of almost all amino acids with a total run time of 12 minutes. Separation of isoleucine and alloisoleucine was incomplete $(R=0.55)$ but without impact on biological interpretation. Precision, accuracy and quantification were satisfactory (intra-days coefficient of variation (CV) was $<5 \%$, inter-days precision CV $<10 \%$ and accuracy $<15 \%$ ). The limits of quantification were validated between 1 and $900 \mu \mathrm{mol} / \mathrm{L}$. Results were comparable between the new method and IEC.

\section{Conclusion}

Ultimately, we validated a rapid method on plasma for quantifying 27 amino acids that can be used in routine practice, according to French quality laboratories and SFEIM (French Society of Inborn Error of Metabolism) recommendations. Furthermore, estimated reference values were similar to those found in published studies focusing on other methods. Despite a lower specificity compared to tandem MS, the simplicity and rapidity of our method are the main advantage of this technique and place it as a major tool in IEM diagnosis and management. 


\section{Introduction}

Inborn errors of metabolism (IEM) are rare diseases, mostly expressed during first months of life and characterised by non-specific clinical signs that can lead to irreversible damage ${ }^{1}$. Patient prognosis will depend on the time of therapeutic initiation, inherent to the reliability of the diagnosis, mainly based on clinical and biological criteria ${ }^{2}$. Furthermore, diseases decompensations may lead to severe outcomes. In all these cases, early treatment is crucial to improve patient support. Measurement of amino acid (AA) concentrations in biological fluids is one of the most crucial explorations to establish diagnosis of AA metabolism abnormalities, urea cycle disorders and other metabolic disorders, but also to monitor therapeutics and diet strategies. Until recently, the gold standard in AA analysis was ion exchange chromatography with ninhydrin post-column derivatisation (IEC). Despite some significant advantages such as repeatability ${ }^{3}$ and broad dynamic range, this technique is characterised by a long analytical time and the use of toxic reagents for detection. Tandem mass spectrometry is also used ${ }^{3-9}$, but this is an expensive technology. A recent method developed with a single quadrupole on plant extracts showed satisfying results concerning AA resolution and quantification ${ }^{10}$. Currently, the French Society of Inborn Errors of Metabolism (SFEIM) recommends providing results to clinicians within 48 hours in cases of suspected metabolic disorders. Moreover, the French obligation to follow the international Norm ISO 15189 for any biological analysis requires internal quality controls (IQC) to be used daily to assess the reliability of results, combined with the regular use of standards to calibrate the analytical method ${ }^{11}$. We suggest that the method presented here and initially developed for nutrition concerns ${ }^{12}$ is of particular interest to fulfil the criteria for quality standards and SFEIM recommendations with acceptable sensitivity and robustness ${ }^{13}$. As this technique has not been initially developed for health concerns, a validation based on ISO 15189 norm and SFEIM recommendations was necessary to use it in clinical practice.

In this context, the objective of this study was to validate a rapid and sensitive method for AA analysis based on a method involving ultra-high performance liquid chromatography coupled to mass 
spectrometry (LC-MS) with derivatisation, according to ISO 15189 recommendations and finally to propose adapted reference values for AA plasma concentrations.

\section{Design and methods}

\subsection{Reagents}

Analytical grade AccQ-Tag kit containing acetonitrile, borate buffer and AQC reagent (6aminoquinolyl-N-hydroxysuccinimidyl carbamate) were purchased from Waters (Millford, MA, USA). Sodium hydroxide $2 \mathrm{M}$, hydrochloric acid $0.1 \mathrm{M}$ and sulfosalicylic acid $10 \%$ solutions were prepared by $\mathrm{NaOH}$ powder, hydrochloric acid 37\% and sulfosalicylic acid dihydrate powder from Sigma Aldrich (St Louis, MO, USA). ULC-MS grade water, acetonitrile and formic acid were purchased from Biosolve (Dieuze, France). As internal standard, we used the MSK-A2 commercial mix from Cambridge Isotopes Laboratories (Tewksbury, MA, USA). The standard solution was prepared for each use, by two AA mixes (A6282 and A6407) obtained from Sigma-Aldrich (St Louis, MO, USA), along with a homemade solution composed of alloisoleucine and glutamine from Sigma-Aldrich (St Louis, MO, USA) to obtain a $1 \mathrm{mmol} / \mathrm{L}$ concentration for each of the $24 \mathrm{AAs}$, with the exception of $500 \mu \mathrm{mol} / \mathrm{L}$ for cystine. A6282 and A6407 were composed respectively of basic AAs (arginine, homocystine, lysine and ornithine) and neutral and acidic AAs (alanine, asparagine, aspartic acid, citrulline, cystine, glutamic acid, glycine, hydroxyproline, isoleucine, leucine, methionine, phenylalanine, proline, serine, taurine, threonine, tyrosine and valine). Six calibration standards were then prepared by serial dilution. Two lyophilised quality control (QC) plasma levels were obtained from Recipe (Munich, Germany) (Table 1). Finally, precipitation reagent was prepared by adding $10 \mu \mathrm{L}$ of internal standard solution to $990 \mu \mathrm{L}$ of sulfosalicylic acid $10 \%$.

\subsection{Samples}

The validation method involved a performance evaluation step and a comparison step. For performance evaluation, we prepared 6 concentrations: $10 \mu \mathrm{M}, 25 \mu \mathrm{M}, 100 \mu \mathrm{M}, 300 \mu \mathrm{M}, 600 \mu \mathrm{M}$ and $900 \mu \mathrm{M}$ for each AA (respectively $5 \mu \mathrm{M}, 12.5 \mu \mathrm{M}, 50 \mu \mathrm{M}, 150 \mu \mathrm{M}, 300 \mu \mathrm{M}$ and $450 \mu \mathrm{M}$ for 
cystine). To compare the new method with an existing tandem MS technique, we collected patients' samples from daily analysis. Blood samples were collected in heparinised tubes and transported to the laboratory within 1 hour in a refrigerated container. The tubes were then centrifuged at $3000 \mathrm{~g}$ for 10 minutes at $5 \pm 3{ }^{\circ} \mathrm{C}$. Plasma was decanted and then frozen at $-20{ }^{\circ} \mathrm{C}$ until analysis.

\subsection{Sample preparation}

First, $100 \mu \mathrm{L}$ of precipitation reagent were added to $50 \mu \mathrm{L}$ of patient's plasma. The mix was then vortexed before one minute to optimise protein precipitation and centrifuged for 10 minutes at $3000 \mathrm{~g}$ at $5{ }^{\circ} \mathrm{C} \pm 3^{\circ} \mathrm{C}$. Ten microliters of supernatant were transferred to an empty MS grade glass vial. Seventy microliters of borate buffer and $20 \mu \mathrm{L}$ of derivatisation reagent were added and the sample was incubated for 10 minutes at $55^{\circ} \mathrm{C}$.

\subsection{LC-single quadrupole mass spectrometer}

Samples were analysed on a Waters UHPLC system consisting of a UHPLC Quaternary Solvent Manager (QSM), a Flow through Needle manager injector (FTN), a column manager oven (CM) and a single quadrupole mass detector (QDA). Separation was performed on a Cortecs UPLC C18 $(1.6 \mu \mathrm{m}$, $2.1 \times 150 \mathrm{~mm}$ ) column maintained at $55^{\circ} \mathrm{C}$ during the analysis. The volume injected on the column was $2 \mu \mathrm{L}$. Gradient elution was performed with constant flow rate $(0.5 \mathrm{~mL} / \mathrm{min})$ using $0.1 \%$ formic acid in water as mobile phase $A$ and $0.1 \%$ formic acid in acetonitrile as mobile phase B. Gradient started at $99 \%$ A and $1 \%$ B during 1 minute. After, mobile phase B increases linearly (curve 6) to $13 \%$ in 1 minute. Then mobile phase B increases to $15 \%$ in 4.5 minutes and finally to $95 \%$ in 2 minutes. This condition is held during 1 minute and then brought back instantaneously to the start condition, which is held during 2.5 minutes.

\subsection{Q-Orbitrap}

Samples were prepared following 6-aminoquinolyl-N-hydroxysuccinimidyl carbamate derivatization as described in "2.3 Sample preparation". Samples were then analysed on a Thermo UHPLC system 
Ultimate 3000 coupled to a high resolution Q-Orbitrap tandem mass spectrometer. Separation was performed on a Cortecs UPLC C18 $(2.7 \mu \mathrm{m}, 3.0 \times 150 \mathrm{~mm})$ column maintained at $55^{\circ} \mathrm{C}$ during the analysis.

\subsection{Triple quadrupole analysis}

Samples were prepared following 6-aminoquinolyl-N-hydroxysuccinimidyl carbamate derivatization as described in "2.3 Sample preparation" purposed AB Sciex. Samples were then analysed on a HPLC 1260 Infinity II (Shimadzu) coupled to a high resolution triple quadrupole 4500 tandem mass spectrometer. Separation was performed on an AB Sciex C18 column.

\subsection{Validation methodology}

\subsubsection{Specificity}

Validation was conducted according to the guidelines of the International Council for Harmonisation $(\mathrm{ICH})^{14}$ and ISO15189 recommendations ${ }^{15}$. First, the specificity of the method was tested by injection of a standard AA solution. All mass channel acquisitions were overlaid. The absence of supplementary peaks and resolution (when necessary) were manually checked. Resolution (R) was calculated as the retention time difference divided by the mean of peak width and should be superior or equal to 1.5 .

\subsubsection{Limit of detection}

Lower and higher limits of quantification were determined as the lower and higher concentrations studied with sufficient precision, accuracy and uncertainty relative to scientific society recommendations $^{16}$ (RICOS; last update in 2014). Pipecolic acid was absent from calibration standards. As pipecolic acid is lower than $5 \mu \mathrm{mol} / \mathrm{L}$ in physiological state ${ }^{17}$, we only established lower limit of detection analysing four levels $(0.5 \mu \mathrm{mol} / \mathrm{L}, 2.5 \mu \mathrm{mol} / \mathrm{L}, 5 \mu \mathrm{mol} / \mathrm{L}$ and $10 \mu \mathrm{mol} / \mathrm{L})$ each day during 6 days to assess precision and accuracy. Lower limit of detection was established as the lower concentration with precision and bias below $20 \%$. 


\subsubsection{Protocol of validation}

Intra-days and inter-days precision, accuracy, uncertainty and measurement range were assessed by the $\beta$-expectation tolerance interval method using Neolicy ${ }^{\circledR}$ software as previously described ${ }^{18}$. Briefly, each validation level was prepared every day for 8 days. Each sample was injected in triplicate. Precisions are reported as coefficient of variation (\%) and uncertainty and accuracy as deviation of the theoretical value (\%). Regarding the 3 following amino acids not systematically quantified: homocitrulline, sulfocysteine, and arginosuccinic acid, each level was analysed during 6 days to assess inter-days precision and accuracy.

The $\beta$-expectation tolerance interval must be included in the specification range to assess the compliance between our methods and recommendations. The confidence interval was calculated with accuracy and inter-day variability. It contained $80 \%$ of predicted measurements for each value. The method is declared conform if $\beta$-expectation tolerance interval is included in recommendations range. Accuracy was also evaluated by quality external evaluation (QEE). QEEs are samples analysed by numerous labs. The results are compared by an independent body. Results are then interpreted according to biases and Z-score (number of standard deviations) to consensus value. Results are considered to be conform if the bias is less than $20 \%$ and if the Z-score is between -2 and 2 . Eight QEEs purchased from ERNDIM were analysed and compared to other labs. In this case, samples were analysed by 292 labs using diverse methods, including LC-MSMS and IEC as well.

\subsubsection{Contamination}

Inter-sample contamination was evaluated by analysing a high-concentration sample (750 $\mu \mathrm{M}$, with the exception of $375 \mu \mathrm{M}$ for cystine) 3 times consecutively ( $\mathrm{H} 1, \mathrm{H} 2, \mathrm{H} 3)$, followed by a lowconcentration sample (50 $\mu \mathrm{M}$, with the exception of $25 \mu \mathrm{M}$ for cystine) (L1, L2, L3). The sequence was repeated 5 times. Then, contamination index was calculated as (mean(L3-L1))/(mean $(\mathrm{H}-\mathrm{L})$ ). Contamination indices were judged acceptable when inferior to $1 \%$. 


\subsubsection{Comparison}

We collected two independent sets of plasma samples from patients explored for diagnostic or metabolic disease monitoring. We compared AA concentrations measured by LC-MS to those measured by IEC (Jeol ${ }^{\circledR}$ Aminotac, as previously published ${ }^{3}$ ) on 38 plasma samples. Furthermore, we compared AA concentrations of 20 other plasma samples measured by LC-MS to those measured by LC-MSMS method performed by the Biochemistry laboratory of the University Hospital of Rennes (France) and by LC-MSMS method in process of accreditation performed by the Biochemistry laboratory of the University Hospital of Angers (France). We analysed the correlation of sample concentrations for each AA between the studied method (LC-MS) and the IEC or LC-MSMS technique using a Bland and Altman plot. Findings were interpreted after comparison with acceptable total error recommended by RICOS. Pipecolic acid was compare only with triple quadrupole methodology with 2.5 and $5 \mu \mathrm{moL} / \mathrm{L}$ spiked samples.

\subsection{Matrix effect}

Ten different plasma samples collected from patients explored in routine practice were spiked with different solutions containing $10 \mu \mathrm{mol} / \mathrm{L}, 25 \mu \mathrm{mol} / \mathrm{L}, 50 \mu \mathrm{mol} / \mathrm{L}$ and $100 \mu \mathrm{mol} / \mathrm{L}$ of each amino acid and were then analysed. Mean recovery was calculated for most of the amino acids. Recovery acceptability was determined as accuracy limits recommended by RICOS.

\subsection{Determination of reference values}

We collected all AA profiles obtained over a one-year period in our Hospital and we excluded each patient known to have a disease or a treatment that could modify AA balance. Finally, 238 results were then divided into classes according to age. It's known that AA concentrations tend to decrease during the first year of life, increasing in some cases between 4 and 6 and after 13-15 years ${ }^{19}$. Accordingly, our results were divided in four classes (0-1 year, 1-4 years, 4-13 years and >13 years). Finally, reference values were determined as the range containing $95 \%$ of AA values in selected samples, according to age class. 


\section{Results}

\subsection{Chromatographic profile}

The analytical method allowed AA separation within 6 minutes out of a total run time of 12 minutes including column equilibration time. All 25 targeted AAs were detected at different masses, resulting in a single peak separated on different acquisition channels. Some exceptions were observed for isobaric AAs (leucine/isoleucine/alloisoleucine and alanine/beta-alanine/sarcosine) as shown in Figure 1. The resolutions were satisfactory however $(R>1.55)$, with the exception of alloisoleucine that was not well-separated from isoleucine $(R=0.55)$ and leucine $(R=1.2)$.

\subsection{Method performance}

Accuracy and precision performances were acceptable according to scientific recommendations (Table 2). Intra-days and inter-days precision ranges were respectively between 0.78 and $3.34 \%$ and between 3.63 and $12.39 \%$. Accuracy was estimated between 1.86 and $12.85 \%$ (in absolute value). For almost all amino acids, these criteria respect RICOS acceptability criteria. Only glutamine had an average bias of $11.82 \%$, whereas RICOS recommended a maximum of $9.45 \%$. Furthermore, the accuracy profile obtained showed stability of the precision and accuracy throughout the measurement range, confirming the satisfactory biases and variability of the method. Confidence ranges were always included in specification ranges (Figure 2). The lower and higher limits of quantification of the method were $1.0 \mu \mathrm{mol} / \mathrm{L}$ and $900 \mu \mathrm{mol} / \mathrm{L}$ for all amino acids including homocitrulline, homocystine and arginosuccinic acid (half for cystine), except pipecolic acid. Precisions obtained on $1 \mu \mathrm{mol} / \mathrm{L}$ sample were estimated between 3.15 and $16.72 \%$ and accuracy between -0.8 and $24.8 \%$, that are considered as acceptable regarding to RICOS values (Table 2).We observed no significant contamination with all contamination indices $<0.25 \%$ (Table 2). QEE results were considered as compliant for almost all AAs (Table 3). Only asparagine, hydroxyproline and taurine were respectively $35 \%, 29 \%$ and $32 \%$ overestimated, while citrulline was $34 \%$ underestimated. Regarding pipecolic acid, lower limit of detection was estimated at $2.5 \mu \mathrm{mol} / \mathrm{L}$. 


\subsection{Recovery and matrix effect}

All recoveries were between $80 \%$ and $120 \%$ for each amino acid. Higher matrix effects were found for phenylalanine $(91 \%)$ and for aspartic acid (119\%). In addition, each bias measured on these samples was lower to uncertainty acceptability. Moreover, matrix effect was stable between different samples (CV between $0.78 \%$ (for alanine) and $10.38 \%$ (for aspartic acids)). Finally, we observed no significant impact of plasma matrix effect on the amino acids analysis with this method.

\subsection{Comparison with other methods}

We obtained a good agreement between the LC-MS and IEC methods. Correlation coefficients $\left(\mathrm{R}^{2}\right)$ were from 0.70 to 0.99 and Bland and Altman analysis confirmed the absence of discordance between both methods (Figure 3). On the other hand, cystine, hydroxyproline and aspartic acid could not be compared due to the fact that too many samples were below the lower limit of quantification for the IEC method. Correlation coefficients between LC-MS and LC-MSMS Q-Orbitrap were between 0.74 and 0.99 . Bland and Altman analysis showed a mean bias of $3.87 \%$, with and only five amino acids (arginine, aspartic acid, cystine, hydroxyproline and taurine) showing a bias $>20 \%$ (Figure 4). Correlation coefficients between LC-MS and LC-MSMS triple quadrupole were between 0.74 and 0.99. Bland and Altman analysis showed a mean bias of $-2.49 \%$ with only glutamic amino acids showing a bias $>20 \%$ (Figure 5). However, these biases were lower than accuracy limits recommended by RICOS (Table 2) and don't have any impact on biological interpretation. Furthermore, $95 \%$ of measured concentrations were included in the acceptable total error range, except aspartic acid for comparison with Q-Orbitrap method (Figure 4) and no discordance were

observed with the triple quadrupole method, except aspartic acid (Figure 5). Unfortunately, sulfocysteine, arginosuccinic acid, homocitrulline, homocystine were not included in these method comparisons as the concentrations of patients samples were under the lower limit of detection. Concerning pipecolic acid detection, no false positive and no false negative have been found.

\subsection{Reference values}


The calculated reference values are shown in Table 4. Some AA concentrations decreased during the first 4 years (taurine, hydroxyproline, and proline) by contrast to branched-chain AA levels that increased during the first year of life. Finally, AA levels were similar between the $4-13$ years and $>13$ years age groups, with the exception of alanine (increasing) and cystine (decreasing).

\section{Discussion}

In this study, we validated an accurate and robust method using LC-MS for the quantification of 27 amino acids in plasma for routine diagnosis and monitoring of metabolic disorders. We also demonstrated that this method was able to detect pipecolic acid from $2.5 \mu \mathrm{mol} / \mathrm{L}$. SFEIM considers pipecolic acid as an important complementary amino acid for IEM diagnosis. Consequently, all samples in which pipecolic acid is detected are sent to another lab for specific quantification.

\subsection{Need for a change of analytical method}

As previously described, underivatised AA methods have benefits but also drawbacks. IEC is an efficient reverse-phase chromatography technique, but involves a processing time (almost 2 hours) that may be incompatible with emergency situations. Over the past years, mass spectrometry (MS) analysis has emerged as an alternative detector for small molecules, including $A A s^{3-5,8-10,20,21}$. Accordingly, different strategies have been tested, but no standard method has been defined and recognized by the various IEM societies or by the consortium of biologists. LC-MS has already shown potential in biological fluids (drug monitoring ${ }^{22}$, steroids ${ }^{23}$ ). Conversely, hydrophilic interaction liquid chromatography (HILIC) allows faster analysis (15-20 minutes ${ }^{24}$ ) but with low separation between leucine, isoleucine and alloisoleucine isobars ${ }^{20}$. Currently, derivatisation would appear to be the best compromise between analysis time, chromatographic resolution and $\operatorname{cost}^{24}$.

\subsection{High technical performance of LCMS (QDA)}

Taking into account both the limits of the previous gold standard method (IEC) and advances in mass spectrometry technologies, we decided to change our analytical method: the new one, based on pre- 
column derivatisation via aminoquinolyl-N-hydroxysuccinimidyl carbamate (AQC), quickly leads to stable products ${ }^{21}$, followed by detection via tandem mass spectrometry after UHPLC separation. This method showed low variability and excellent accuracy. Intra-days and inter-days precision values were comparable or sometimes even lower than the variability found in other studies quantifying AA by liquid chromatography coupled to mass spectrometry ${ }^{5,7}$. Lower and upper limits of quantification were in line with clinical needs for all AAs. Even though diagnosis is not based on a single amino acid, and often revealed by high AA concentrations, quantification down to $1 \mu \mathrm{mol} / \mathrm{L}$ can be important to help in some diagnoses and to initiate treatment earlier ${ }^{25}$. For example, in the case of MTHFR deficiency, methionine levels are decreased at birth and can be at almost $1 \mu \mathrm{mol} / \mathrm{L}^{26}$. Similarly plasma citrulline (Cit) and arginine (Arg) concentrations may also be lower than $1 \mu \mathrm{mol} / \mathrm{L}$ in ornithine transcarbamylase (OTC) deficiency ${ }^{27}$. Accordingly, some studies have estimated that high sensitivity (lower limit of quantification between 1.3 and $5.3 \mu \mathrm{mol} / \mathrm{L}^{21,28}$ ) may be of interest for some AAs. A dilution protocol will be required for AA concentrations that could be higher than the upper limit of quantification, at least for phenylalanine, glutamine and leucine, that can be higher than $1000 \mu \mathrm{M}$ respectively in phenylketonuria ${ }^{29}$, urea cycle disorders ${ }^{30}$ and Maple Syrup Urine Disease (MSUD) ${ }^{31}$.

We found a good correlation of the concentrations measured by mass spectrometry and ion exchange chromatography with ninhydrin post-column derivatisation ${ }^{3,20}$. Even though the QEE results were not satisfactory for four AAs, the difference can be explained by the variability of the analytical method used by the different laboratories (IEC, LCMSMS, LCMS, etc.), as shown in table 4. Moreover, Casado et al previously showed a poor level of correlation between LCMSMS and IEC for hydroxyproline, aspartic acid and citrulline, that could explain these differences between laboratories $^{32}$. However, comparison between LC-MS and LC-MSMS showed mean bias lower than $20 \%$ except for aspartic acid, arginine, hydroxyproline, cystine and taurine. Furthermore, even for these five amino acids, the uncertainty met RICOS recommendations. In most of the cases, this deviation has no significant impact on the biological interpretation. However, we have to be careful with these amino-acids and those that have low concentrations. We must be aware of the lower 
specificity of single MS compared to tandem MS, and we highly recommend the re-analysis of samples in case of inconsistence between clinical and biological data. Moreover, recovery was stable between samples and linearity was conserved between different spiked solutions. We can conclude that matrix effect doesn't have any significant effect on plasma amino acids analysis. In addition, as we have estimated new reference values biological interpretation is not impacted. Finally, we noted the absence of contamination, thus completing the validation of the new technique. However, IEM diagnosis can be also provided based on amino acids analysis in urine and in CSF. In both matrixes, some amino acid concentration may be found lower to $1 \mu \mathrm{mol} / \mathrm{L}$. Even if simple quadrupole mass spectrometry is in agreement with all recommendations concerning plasmatic amino acids analysis, it should be evaluated for CSF and urine samples to evaluate its place in metabolism disorders investigations.

\subsection{Main advantages of UHPLC -mass spectrometry (QDA) in clinical practice}

Sample preparation has the advantage of being simple and rapid (no more than 30 minutes). Finally, the total analysis time of only 12 minutes, compatible with regular calibration with multiple standards and daily control analysis as imposed by the French quality committee and ISO15189 standard ${ }^{11}$ is in line with metabolic emergency and allows the analysis of numerous samples per day as required. One of the most common limitations of MS techniques for AA exploration is the separation of the branched-chain AAs leucine and isoleucine. This was a crucial validation point, especially to diagnose and follow patients suffering from Maple Syrup Urine Disease (MSUD), characterised by a deficiency in branched-chain alpha-keto acid dehydrogenase required to metabolise branched-chain AAs (BCAAs). A recent study has shown that early diagnosis, combined with a restrictive diet and close leucine monitoring, have a significant effect on neurological evolution $^{31}$. Furthermore, the treatment of many metabolic disorders is based on protein intake control and plasmatic BCAAs are crucial parameters to evaluate nutrition status. For this, BCAA separation and specificity is an advantage over other techniques that quantify the sum of both. As 
described in urea cycle disorders ${ }^{33}$ or phenylketonuria ${ }^{34}$, the specific diet (low protein diet) requires regular and strict monitoring of BCAA (and other essential AAs) to avoid deficiencies and at the same time to allow the correct growth of children ${ }^{35}$.

\subsection{Main limits of the study}

The proposed method for metabolic disease screening based on simple quadrupole mass spectrometry has shown satisfying results, regarding to SFEIM organization and RICOS requirements. The proposed single quadrupole analysis should be associated, as previously described to a triple quadrupole analysis to validate unexpected results and to exclude occasional interferences, notably for low concentrated plasma amino acids. The clinical interpretation of amino acids analysis is made from the interpretation of a global profile, but for some amino acids that we cannot quantitate at low levels, we send the sample to another laboratory for accurate quantification. As for the incomplete chromatographic separation of alloisoleucine and isoleucine, we assume that alloisoleucine levels are usually relatively high and recognizable compared to isoleucine in the affected patients. Finally, we have compared 2 series of 20 samples between our method and other MS methods and the results were correct. We could test false positives and negatives in more samples than is required for accreditation purposes and we could regularly plan this kind of cross validation, . The comparison of methods presented on a large number of samples and the satisfying results of external quality controls ensure the reliability of the technique. Finally, as CSF samples have not been evaluated in this study, and because amino acids concentrations are lower than in plasma samples, we recommend to use a validated method on tandem MS.

\subsection{Reference values}

As shown in Table 5, Nakamura et $a^{36}$ described similar reference values in various Asian populations. In this study, the AA concentrations of Japanese, Korean and Chinese populations 
according to gender, age and body mass index were compared. Only glutamine was significantly different $(p=0.0013)$. This study, however, was conducted exclusively on an Asian population. By contrast, reference values seem to be different between the studies of Casado et al ${ }^{32}$ and Filee et $a l^{6}$, respectively conducted on Spanish and Belgian populations (Table 5). We suggest that this difference is a combination of the variability of local analytical methods and of population variations. Furthermore, AA concentrations evolve according to age ${ }^{37}$. Even though numerous studies have grouped reference values into different age classes, there is no consensus concerning their limits $^{6,32,38}$. Reference values are difficult to estimate because of the difficulty obtaining nonpathological samples in hospitals. Furthermore, AA concentrations are governed by daily nutrition, activity $^{39}$ and associated diseases ${ }^{40}$. Finally, concentrations appear to differ according to analytical method (IEC, LCMSMS, LCMS, etc.) and population tested (ethnic group, age, etc.). Thus, we recommend estimating new reference values for each validated method and checking the extent of the discrepancy. Our calculated reference values were comparable to those previously published in LCMSMS methods ${ }^{6,32,36,38,41}$ whatever the age class. We also confirmed the evolution of AA concentrations over the first years of life.

\section{Conclusion}

In this study, we validated an LCMS method to quantify 27 amino acids in 12 minutes according to French quality committee criteria. This method allows the separation of all amino acids (except leucine, isoleucine and alloisoleucine) with a satisfactory degree of precision and accuracy, allowing their quantification between 1.0 and $900 \mu \mathrm{mol} / \mathrm{L}$. Even if separation of isoleucine, allosisoleucine and leucine was incomplete, our method is able to quantify these three amino acids, without impact on biological interpretation. Pipecolic acid detection was established at $2.5 \mu \mathrm{mol} / \mathrm{L}$ without testing quantification performances. Finally, we estimated our reference values on samples from patients without known metabolic disorders. This method also allows daily use for diagnosis and monitoring of metabolic diseases according to minimum requirements and plays a crucial role in IEM screening despite the need of triple quadrupole in some contexts. 


\section{References}

1. Touati, G. et al. Methylmalonic and propionic acidurias: management without or with a few supplements of specific amino acid mixture. J. Inherit. Metab. Dis. 29, 288-298 (2006).

2. Palermo, L. et al. Cognitive outcomes in early-treated adults with phenylketonuria (PKU): A comprehensive picture across domains. Neuropsychology 31, 255-267 (2017).

3. Smon, A. et al. Comparison of liquid chromatography with tandem mass spectrometry and ionexchange chromatography by post-column ninhydrin derivatization for amino acid monitoring. Clin. Chim. Acta 495, 446-450 (2019).

4. Carling, R. S., John, K., Churchus, R., Turner, C. \& Dalton, R. N. Validation of a rapid, comprehensive and clinically relevant amino acid profile by underivatised liquid chromatography tandem mass spectrometry. Clin. Chem. Lab. Med. (2019) doi:10.1515/cclm-2019-0604.

5. Dietzen, D. J. et al. Rapid comprehensive amino acid analysis by liquid chromatography/tandem mass spectrometry: comparison to cation exchange with post-column ninhydrin detection. Rapid Commun. Mass Spectrom. RCM 22, 3481-3488 (2008).

6. Filee, R., Schoos, R. \& Boemer, F. Evaluation of physiological amino acids profiling by tandem mass spectrometry. JIMD Rep. 13, 119-128 (2014).

7. Harder, U., Koletzko, B. \& Peissner, W. Quantification of 22 plasma amino acids combining derivatization and ion-pair LC-MS/MS. J. Chromatogr. B Analyt. Technol. Biomed. Life. Sci. 879, 495-504 (2011).

8. Kritikos, N., Tsantili-Kakoulidou, A., Loukas, Y. L. \& Dotsikas, Y. Liquid chromatography coupled to quadrupole-time of flight tandem mass spectrometry based quantitative structure-retention relationships of amino acid analogues derivatized via $\mathrm{n}$-propyl chloroformate mediated reaction. J. Chromatogr. A 1403, 70-80 (2015).

9. Krumpochova, P. et al. Amino acid analysis using chromatography-mass spectrometry: An inter platform comparison study. J. Pharm. Biomed. Anal. 114, 398-407 (2015). 
10. Dahl-Lassen, R. et al. High-throughput analysis of amino acids in plant materials by single quadrupole mass spectrometry. Plant Methods 14, 8 (2018).

11. $14: 00-17: 00$. ISO 15189:2012. ISO

http://www.iso.org/cms/render/live/fr/sites/isoorg/contents/data/standard/05/61/56115.html.

12. Bosch, L., Alegría, A. \& Farré, R. Application of the 6-aminoquinolyl-N-hydroxysccinimidyl carbamate (AQC) reagent to the RP-HPLC determination of amino acids in infant foods. J. Chromatogr. B Analyt. Technol. Biomed. Life. Sci. 831, 176-183 (2006).

13. la Cour, R., Jørgensen, H. \& Schjoerring, J. K. Improvement of Tryptophan Analysis by Liquid Chromatography-Single Quadrupole Mass Spectrometry Through the Evaluation of Multiple Parameters. Front. Chem. 7, 797 (2019).

14. Ich, I. Q2 (R1): Validation of analytical procedures: text and methodology. in (2005).

15. Vassault, A. \& membres du sous-groupe Management de la qualité. [Evaluation of the quality management system according to the standard EN ISO 15 189: 2012. Proposition for a greed]. Ann. Biol. Clin. (Paris) 71 Spec No 1, 177-187 (2013).

16. Current databases on biological variation: pros, cons and progress. - PubMed - NCBI. https://www.ncbi.nlm.nih.gov/pubmed/10667686 (2020).

17. Baas, J. C. M. et al. Plasma pipecolic acid is frequently elevated in non-peroxisomal disease. J. Inherit. Metab. Dis. 25, 699-701 (2002).

18. Feinberg, M. Mise en œuvre du profil d'exactitude. 18 (2010).

19. Lepage, N., McDonald, N., Dallaire, L. \& Lambert, M. Age-specific distribution of plasma amino acid concentrations in a healthy pediatric population. Clin. Chem. 43, 2397-2402 (1997).

20. Prinsen, H. C. M. T. et al. Rapid quantification of underivatized amino acids in plasma by hydrophilic interaction liquid chromatography (HILIC) coupled with tandem mass-spectrometry. J. Inherit. Metab. Dis. 39, 651-660 (2016).

21. Sharma, G. et al. Analysis of 26 amino acids in human plasma by HPLC using AQC as derivatizing agent and its application in metabolic laboratory. Amino Acids 46, 1253-1263 (2014). 
22. Musijowski, J., Filist, M. \& Rudzki, P. J. Sensitive single quadrupole LC/MS method for determination of lapatinib in human plasma. Acta Pol. Pharm. 71, 1029-1036 (2014).

23. Bus-Kwasnik, K., Filist, M. \& Rudzki, P. J. ENVIRONMENTALLY FRIENDLY LC/MS DETERMINATION OF EPLERENONE IN HUMAN PLASMA. Acta Pol. Pharm. 73, 1487-1493 (2016).

24. Ferré, S., González-Ruiz, V., Guillarme, D. \& Rudaz, S. Analytical strategies for the determination of amino acids: Past, present and future trends. J. Chromatogr. B Analyt. Technol. Biomed. Life. Sci. 1132, 121819 (2019).

25. Dieckman, E., de Koning, T., Verhoeven-Duif, N. M., Rovers, M. \& van Hasselt, P. M. Survival and psychomotor development with early betaine treatment in patients with severe methylenetetrahydrofolate reductase deficiency. - PubMed - NCBI. https://www-ncbi-nlm-nihgov.proxy.insermbiblio.inist.fr/pubmed/24323041?dopt=Abstract.

26. Nishimoto, E., Ito, Y., Sakakibara, T. \& Nishikubo, T. Early treatment using betaine and methionine for a neonate with MTHFR deficiency. Pediatr. Int. 61, 1265-1266 (2019).

27. Lichter-Konecki, U., Caldovic, L., Morizono, H. \& Simpson, K. Ornithine Transcarbamylase Deficiency. in GeneReviews ${ }^{\circledast}$ (eds. Adam, M. P. et al.) (University of Washington, Seattle, 1993).

28. Kaspar, H., Dettmer, K., Gronwald, W. \& Oefner, P. J. Advances in amino acid analysis. Anal. Bioanal. Chem. 393, 445-452 (2009).

29. Yuskiv, N. et al. Nutritional management of phenylalanine hydroxylase (PAH) deficiency in pediatric patients in Canada: a survey of dietitians' current practices. Orphanet J. Rare Dis. 14, 7 (2019).

30. Lee, B. et al. Glutamine and hyperammonemic crises in patients with urea cycle disorders. Mol. Genet. Metab. 117, 27-32 (2016).

31. Couce, M. L. et al. Evolution of maple syrup urine disease in patients diagnosed by newborn screening versus late diagnosis. Eur. J. Paediatr. Neurol. EJPN Off. J. Eur. Paediatr. Neurol. Soc. 19, 652-659 (2015). 
32. Casado, M., Sierra, C., Batllori, M., Artuch, R. \& Ormazabal, A. A targeted metabolomic procedure for amino acid analysis in different biological specimens by ultra-high-performance liquid chromatography-tandem mass spectrometry. Metabolomics Off. J. Metabolomic Soc. 14, 76 (2018).

33. Adam, S. et al. Dietary management of urea cycle disorders: UK practice. J. Hum. Nutr. Diet. 25, 398-404 (2012).

34. Singh, R. H. et al. Recommendations for the nutrition management of phenylalanine hydroxylase deficiency. Genet. Med. 16, 121-131 (2014).

35. van Wegberg, A. M. J. et al. The complete European guidelines on phenylketonuria: diagnosis and treatment. Orphanet J. Rare Dis. 12, (2017).

36. Nakamura, H. et al. Plasma amino acid profiles in healthy East Asian subpopulations living in Japan. Am. J. Hum. Biol. 28, 236-239 (2016).

37. Méndez, J. A., Fernández-Sanmamed, A. L., Gómez-Holgado, M. S. \& Fernández-Rodríguez, F. Age-related reference values for plasma amino acids in a Spanish population measured by gas chromatography-mass spectrometry. J. Pediatr. Endocrinol. Metab. JPEM 26, 333-341 (2013).

38. Akiyama, T., Kobayashi, K., Higashikage, A., Sato, J. \& Yoshinaga, H. CSF/plasma ratios of amino acids: Reference data and transports in children. Brain Dev. 36, 3-9 (2014).

39. Felder, T. K. et al. Specific circulating phospholipids, acylcarnitines, amino acids and biogenic amines are aerobic exercise markers. J. Sci. Med. Sport 20, 700-705 (2017).

40. Li, Y. et al. Alterations of amino acid metabolism in osteoarthritis: its implications for nutrition and health. Amino Acids 48, 907-914 (2016).

41. Peng, M.-Z. et al. Simultaneous quantification of 48 plasma amino acids by liquid chromatography-tandem mass spectrometry to investigate urea cycle disorders. Clin. Chim. Acta Int. J. Clin. Chem. 495, 406-416 (2019). 


\begin{tabular}{|c|c|c|}
\hline & Level 1 & Level 2 \\
\hline Hydroxy-proline & $7.30-10.9$ & $44.6-66.9$ \\
\hline Asparagine & $32.2-48.3$ & $148-222$ \\
\hline Arginine & $23.2-34.6$ & $205-307$ \\
\hline Taurine & $35.6-53.4$ & $161-218$ \\
\hline Serine & $80.4-121$ & $247-334$ \\
\hline Glutamine & $359-538$ & $756-1134$ \\
\hline Glycine & $165-230$ & $533-800$ \\
\hline Aspartic acid & $7.17-13.3$ & $83.9-126$ \\
\hline Glutamic acid & $83.4-125$ & $166-249$ \\
\hline Citrulline & $19.3-28.9$ & $102-138$ \\
\hline Threonine & $96.3-130$ & $178-241$ \\
\hline Alanine & $351-475$ & $589-796$ \\
\hline Proline & $185-278$ & $392-530$ \\
\hline Ornithine & $118-160$ & $284-384$ \\
\hline Lysine & $136-204$ & $216-324$ \\
\hline Tyrosine & $52.2-78.4$ & $170-230$ \\
\hline Methionine & $23.3-34.9$ & $57.0-77.1$ \\
\hline Valine & $203-275$ & $368-498$ \\
\hline Isoleucine & 70.2 - 95 & $111-150$ \\
\hline Alloisoleucine & $13.3-24.7$ & $149-223$ \\
\hline Leucine & $119-178$ & $232-349$ \\
\hline Phenylalanine & $67.2-90.9$ & $358-484$ \\
\hline
\end{tabular}

Table 1: Amino acids reference values for QC plasma samples 


\begin{tabular}{|c|c|c|c|c|c|c|c|c|c|c|}
\hline \multirow{2}{*}{ Compound } & \multicolumn{2}{|c|}{$\begin{array}{c}\text { Intra-days } \\
\text { precision (\%) }\end{array}$} & \multicolumn{2}{|c|}{$\begin{array}{c}\text { Inter-days } \\
\text { precision (\%) }\end{array}$} & \multicolumn{2}{|c|}{ Accuracy (\%) } & \multicolumn{2}{|c|}{ Uncertainty (\%) } & \multirow{2}{*}{$\frac{\text { Recovery }}{(\%)}$} & \multirow{2}{*}{$\frac{\text { Contamination }}{(\%)}$} \\
\hline & RICOS & Mean & RICOS & Mean & RICOS & Mean & RICOS & Mean & & \\
\hline Hydroxy-proline & 19.50 & 3.10 & 25.90 & 6.86 & 24.90 & 4.41 & 76.70 & 15.15 & 102.1 & 0.08 \\
\hline Asparagine & 6.90 & 2.07 & 9.20 & 8.52 & 11.40 & 10.84 & 29.80 & 20.46 & 94.4 & 0.24 \\
\hline Arginine & 10.90 & 3.34 & 14.50 & 5.71 & 14.70 & 3.49 & 43.70 & 12.45 & 98.5 & 0.01 \\
\hline Taurine & 17.30 & 3.11 & 22.95 & 6.92 & 20.10 & 4.45 & 66.00 & 15.37 & 105.2 & 0.07 \\
\hline Serine & 7.20 & 2.33 & 9.60 & 4.73 & 16.80 & 7.15 & 36.00 & 10.79 & 99.5 & 0.01 \\
\hline Glutamine & 6.80 & 1.98 & 9.10 & 4.14 & 9.45 & 11.82 & 27.65 & 9.91 & 99.4 & 0.07 \\
\hline Glycine & 6.70 & 1.98 & 8.85 & 3.88 & 15.75 & 5.84 & 33.45 & 9.07 & 101.6 & 0.10 \\
\hline Aspartic acid & 17.60 & 1.55 & 23.40 & 4.43 & 23.70 & 5.02 & 70.50 & 10.00 & 109.1 & 0.07 \\
\hline Glutamic acid & 15.47 & 2.09 & 23.20 & 4.05 & 23.12 & 5.34 & 69.52 & 9.09 & 97.8 & 0.01 \\
\hline Citrulline & 12.00 & 3.34 & 16.00 & 5.71 & 18.30 & 3.49 & 50.30 & 12.45 & 97.5 & 0.08 \\
\hline Threonine & 10.10 & 2.31 & 13.40 & 4.52 & 14.10 & 4.33 & 40.90 & 9.96 & 99.7 & 0.05 \\
\hline Alanine & 8.30 & 2.39 & 11.00 & 4.34 & 21.60 & 7.26 & 43.60 & 10.21 & 100.5 & 0.11 \\
\hline Proline & 9.60 & 2.01 & 12.80 & 4.10 & 39.60 & 3.33 & 65.20 & 8.95 & 100.3 & 0.11 \\
\hline Ornithine & 10.40 & 2.43 & 13.80 & 5.75 & 21.80 & 12.85 & 49.40 & 13.76 & 98.3 & 0.02 \\
\hline Cystine & 21.60 & 2.41 & 28.70 & 5.31 & 23.10 & 1.86 & 80.50 & 11.43 & 99.8 & 0.12 \\
\hline Lysine & 6.80 & 1.66 & 8.60 & 4.52 & 15.00 & 5.99 & 32.20 & 10.17 & 101.7 & 0.02 \\
\hline Tyrosine & 5.90 & 0.94 & 7.90 & 3.67 & 23.25 & 2.84 & 39.05 & 8.04 & 98.4 & 0.01 \\
\hline Methionine & 8.30 & 0.88 & 11.00 & 3.76 & 17.30 & 3.93 & 39.30 & 8.33 & 98.3 & 0.03 \\
\hline Valine & 6.00 & 0.78 & 8.00 & 3.74 & 15.60 & 3.50 & 31.60 & 8.25 & 99.3 & 0.10 \\
\hline Homocystine & 4.15 & 1.69 & 8.30 & 5.83 & 8.63 & 5.00 & 25.23 & 13.65 & - & 0.02 \\
\hline Isoleucine & 8.70 & 1.17 & 11.60 & 3.70 & 18.00 & 3.02 & 41.20 & 8.32 & 100.7 & 0.00 \\
\hline Alloisoleucine & $10.00 *$ & 1.53 & $15.00 *$ & 5.63 & $20.00 *$ & 3.07 & $50.00 *$ & 12.39 & - & 0.03 \\
\hline Leucine & 8.30 & 0.83 & 11.10 & 3.68 & 17.40 & 3.11 & 39.60 & 8.08 & 100.0 & 0.02 \\
\hline Phenylalanine & 5.40 & 0.78 & 7.10 & 3.67 & 15.60 & 3.08 & 29.80 & 8.07 & 99.1 & 0.04 \\
\hline Homocitrulline & $10.00 *$ & - & $15.00 *$ & 3.63 & $20.00 *$ & -5.38 & $50.00 *$ & - & - & - \\
\hline Sulfocysteine & $10.00 *$ & - & $15.00 *$ & 12.39 & $20.00 *$ & -2.52 & $50.00 *$ & - & - & - \\
\hline $\begin{array}{c}\text { Arginosuccinic } \\
\text { acid }\end{array}$ & $10.00 *$ & - & $15.00 *$ & 10.60 & $20.00 *$ & 1.07 & $50.00 *$ & - & - & - \\
\hline
\end{tabular}

Table 2: Method performances for the quantitative analysis of 24 amino acids

*: Absence of recommendations from RICOS. These limits are based on FDA recommendations for chromatographic methods 


\begin{tabular}{|c|c|c|c|}
\hline \multirow[t]{3}{*}{ Analyte } & \multicolumn{3}{|c|}{ Accuracy } \\
\hline & \multicolumn{2}{|c|}{ (mean) } & \multirow{2}{*}{$\frac{\text { (deviation) }}{\%}$} \\
\hline & Our Lab & All labs & \\
\hline Alanine & 732 & 723 & +1.24 \\
\hline Arginine & 297 & 276 & +7.61 \\
\hline Asparagine & 78.9 & 64.7 & +21.95 \\
\hline Aspartic Acid & 52.2 & 55.9 & -6.62 \\
\hline Citrulline & 367 & 512 & -28.32 \\
\hline Cystine & 51.2 & 55.2 & -7.25 \\
\hline Glutamic acid & 118 & 116 & +1.72 \\
\hline Glutamine & 801 & 778 & +2.96 \\
\hline Glycine & 563 & 556 & +1.26 \\
\hline Histidine & 173 & 169 & +2.37 \\
\hline Hydroxy-proline & 59.2 & 44.5 & +33.03 \\
\hline Isoleucine & 377 & 353 & +6.80 \\
\hline Leucine & 336 & 324 & +3.70 \\
\hline Lysine & 217 & 214 & +1.40 \\
\hline Methionine & 318 & 307 & +3.58 \\
\hline Ornithine & 294 & 259 & +13.51 \\
\hline Phenylalanine & 369 & 341 & +8.21 \\
\hline Proline & 382 & 366 & +4.37 \\
\hline Serine & 206 & 198 & +4.04 \\
\hline Taurine & 262 & 202 & +29.70 \\
\hline Threonine & 199 & 200 & -0.50 \\
\hline Tyrosine & 251 & 239 & +5.02 \\
\hline Valine & 312 & 301 & +3.65 \\
\hline
\end{tabular}

Table 3: Mean results of QEE and deviation (in percentage) relative to results from all participating labs $(n>200)$ 


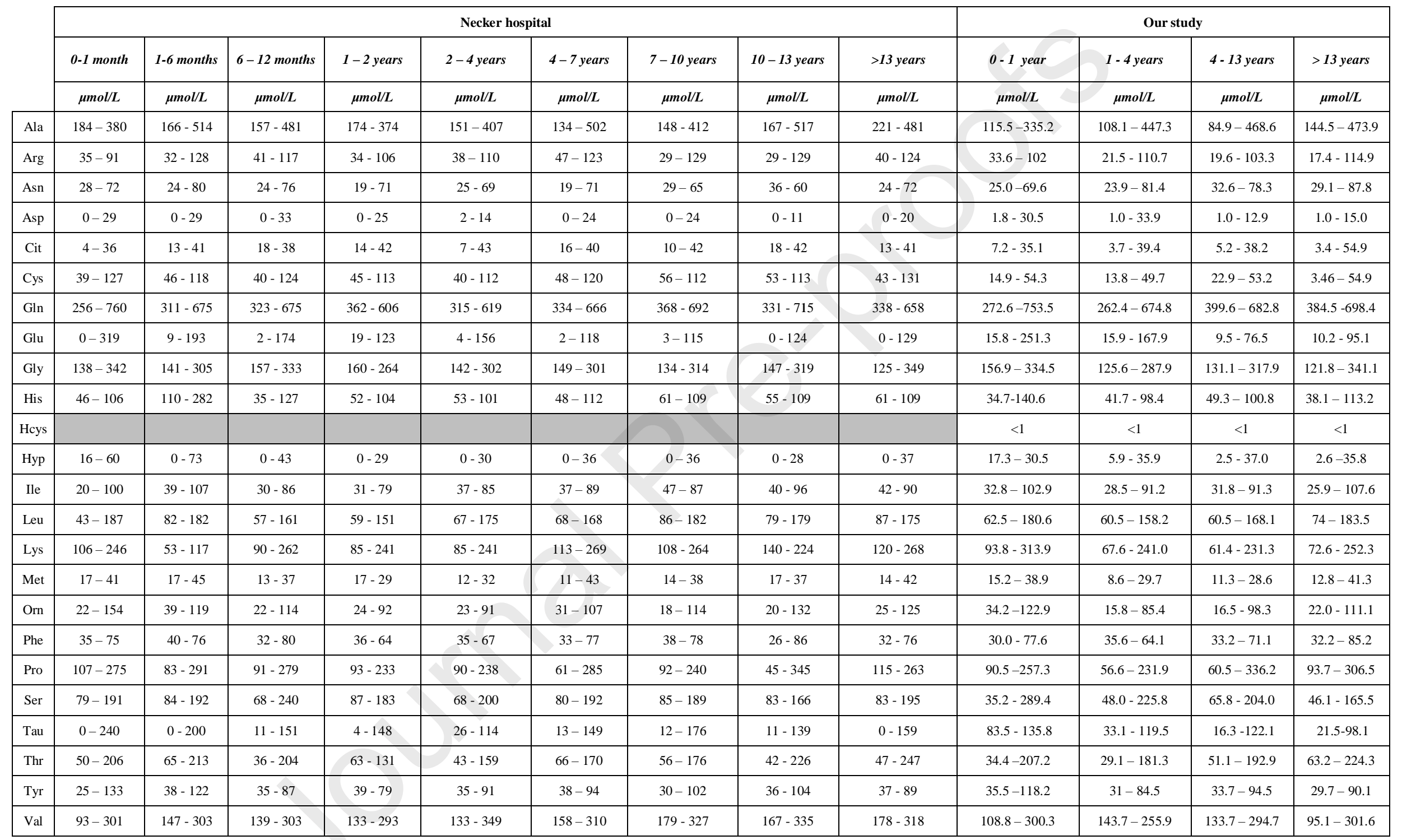

Table 4: Amino acids age-related reference values in plasma in French population. Necker values were estimated by Necker hospital (Paris) by IEC 


\begin{tabular}{|c|c|c|c|c|c|c|c|c|c|c|c|c|c|c|c|}
\hline & \multicolumn{3}{|c|}{ Filee et all $2014^{6}$} & \multicolumn{3}{|c|}{ Casado et all $2018^{32}$} & \multicolumn{3}{|c|}{ Nakamura et al $\mathbf{2 0 1 6}^{36}$} & \multicolumn{2}{|c|}{ Akiyama et al, $\mathbf{2 0 1 4}^{38}$} & \multicolumn{4}{|c|}{ M.Z Peng et al2019 ${ }^{41}$} \\
\hline & $0-2$ years & $2-12$ years & $\begin{array}{l}>=12 \\
\text { years }\end{array}$ & 0-1 month & $\begin{array}{c}2 \text { months- } \\
2 \text { years }\end{array}$ & $>2$ years & Japanese & Korean & Chinese & $0-3$ years & $>3$ years & 0 - 1year & $1-3$ years & 3 - 6 years & $6-15$ years \\
\hline & $\mu m o l / L$ & $\mu m o l / L$ & $\mu \mathrm{mol} / \mathrm{L}$ & $\mu m o l / L$ & $\mu \mathrm{mol} / \mathrm{L}$ & $\mu m o l / L$ & $\mu m o l / L$ & $\mu m o l / L$ & $\mu m o l / L$ & $\mu m o l / L$ & $\mu m o l / L$ & $\mu \mathrm{mol} / \mathrm{L}$ & $\mu m o l / L$ & $\mu m o l / L$ & $\mu m o l / L$ \\
\hline Ala & $122-426$ & $111-518$ & $153-592$ & $190-337$ & \multicolumn{2}{|c|}{$167-439$} & $250.1-595.6$ & $241.7-671.3$ & $196.2-681.5$ & $236-484$ & $246-506$ & $221.8-550$ & $156.9-475.1$ & $167.3-475.6$ & $191.6-522.9$ \\
\hline $\operatorname{Arg}$ & $14.4-164$ & 18.4-102 & $11.2-128$ & \multicolumn{3}{|c|}{$47-122$} & $53.6-138.6$ & $69.5-135.8$ & $59.6-151.2$ & $49.0-100.8$ & $44.4-99.8$ & $30.6-115.7$ & $14.7-119$ & $29-113.7$ & $23.5-120.1$ \\
\hline Asn & $27.1-123$ & $28.4-102$ & $22.7-115$ & \multicolumn{3}{|c|}{$31-120$} & $38.0-65.1$ & $34.2-71.5$ & $33.9-71.8$ & $33.0-68.4$ & $36.4-59.6$ & $32.6-71.3$ & $24.2-71.3$ & $29.8-76.7$ & $28-79.9$ \\
\hline Asp & $6.1-69.4$ & $4.6-60.3$ & $4.4-65$ & \multicolumn{3}{|c|}{$2-20$} & & & & $2.1-8.5$ & $0.8-6.4$ & $3.5-11$ & $2.8-12.9$ & $2.2-12.7$ & $3-7.4$ \\
\hline Cit & 7.9-33.6 & $8.4-40.7$ & $13.5-63.3$ & \multicolumn{3}{|c|}{$8-40$} & $17.5-41.7$ & $19.6-46.5$ & $16.5-42.9$ & & & $14.7-40$ & $13.6-32.8$ & $17.4-41.2$ & $15.1-34.5$ \\
\hline Cys & $6.4-124$ & $0.9-39.1$ & $7.3-58.5$ & \multicolumn{3}{|c|}{$15-59$} & & & & $26.7-51.7$ & 37.9-57.9 & & & & \\
\hline Gln & $336-691$ & $300-688$ & $296-884$ & $326-750$ & $325-676$ & $330-632$ & $474.8-743.8$ & $402.4-706.4$ & $437.7-700.0$ & $450.1-644.7$ & $423.3-572.5$ & $287.7-588.5$ & $331.5-565.5$ & $360.2-566.3$ & $294.3-625.6$ \\
\hline Glu & $38-353$ & $35-288$ & $41.9-236$ & \multicolumn{3}{|c|}{$5-80$} & $10.1-50.3$ & $8.3-64.9$ & $11.7-86.7$ & $48.4-103.4$ & $32.8-68.2$ & $39.8-134.2$ & $36.4-97.4$ & $36.8-95.6$ & $31.5-113.1$ \\
\hline Gly & $113-458$ & $164.7-402$ & 94.9-463 & \multicolumn{3}{|c|}{$109-293$} & 95.3-397.7 & $119.1-381.0$ & $166.1-326.0$ & $153.6-281.6$ & $216.8-406.0$ & $110.5-271.7$ & $92.7-307.4$ & $136.9-252.4$ & $90.1-286.4$ \\
\hline His & $35-117$ & $34.2-114$ & $35.4-136.2$ & \multicolumn{3}{|c|}{$45-104$} & $65.5-106.0$ & $63.9-99.2$ & $68.1-98.0$ & $57.0-82.4$ & $59.1-93.5$ & $60-116.3$ & $61-116.6$ & $59.6-108.9$ & $50.1-116.5$ \\
\hline Нyp & $10.8-76.2$ & $8.7-31.9$ & $4.8-34.6$ & \multicolumn{2}{|c|}{$12-99$} & $5-40$ & & & & & & $17.8-48.1$ & $12.1-37.4$ & $12.1-44$ & $8.7-51.2$ \\
\hline Ile & $30.3-129$ & $24.7-94.7$ & $28.3-167.8$ & \multicolumn{3}{|c|}{$32-90$} & $38.0-115.3$ & $33.6-104.2$ & $42.8-96.7$ & $50.6-89.8$ & $48.7-92.7$ & $39.8-149.9$ & $39.8-115.4$ & $37.4-163.9$ & $50.8-154.5$ \\
\hline Leu & 44.9-198 & 44.5-158 & $61.2-203.8$ & \multicolumn{3}{|c|}{$57-155$} & $70.1-206.0$ & $67.7-169.3$ & $85.2-177.1$ & $90.9-148.6$ & $95.9-163.1$ & $65.7-250.7$ & $75.9-196.9$ & $70.7-248.9$ & $89-257.5$ \\
\hline Lys & $64.5-375$ & $75.5-228$ & $105-253$ & $67-252$ & \multicolumn{2}{|c|}{$112-240$} & $113.0-255.2$ & $131.8-249.7$ & $102.6-276.7$ & $97.6-199.0$ & $130.6-216.8$ & $105.2-271.5$ & $71.8-242.1$ & $117.6-272.2$ & $111.5-213.6$ \\
\hline Met & $9.4-67.6$ & $9.3-31$ & $9.6-44.4$ & \multicolumn{3}{|c|}{$12-37$} & $18.5-44.5$ & $18.5-40.6$ & $13.6-47.3$ & $15.7-32.3$ & $16.7-33.5$ & $13.4-59.6$ & $9.5-50.9$ & $11.1-51.8$ & $10.7-36.1$ \\
\hline Orn & 19.9-181 & $23.4-165$ & $42.8-186$ & \multicolumn{2}{|c|}{$30-175$} & $30-109$ & $17.8-83.3$ & $26.6-79.7$ & $24.2-83.5$ & & & $41.3-136.4$ & $38.1-117.7$ & $41-135.5$ & $59.1-156.4$ \\
\hline Phe & $25.5-131$ & $27.7-95.8$ & 23.5-104 & \multicolumn{3}{|c|}{$40-70$} & $45.5-89.5$ & $40.0-78.2$ & $46.3-88.8$ & $34.7-67.5$ & $42.2-70.4$ & $40.1-94.7$ & $47.2-80.8$ & $47-95.2$ & $48.2-88.9$ \\
\hline Pro & 74.9-276 & $89.2-286$ & $85.8-327.8$ & \multicolumn{3}{|c|}{$90-355$} & $67.1-271.2$ & $97.2-272.7$ & $73.2-348.2$ & $140.3-272.9$ & $107.9-302.1$ & $109.1-283.7$ & $74.5-304.7$ & $99-331.1$ & $80.1-358.1$ \\
\hline Ser & $62-253$ & $61.8-230$ & $53.7-216$ & \multicolumn{3}{|c|}{$92-197$} & $62.1-179.1$ & $82.4-166.5$ & $80.3-161.1$ & $120.2-177.8$ & $125.2-180.4$ & $101.3-206.4$ & $77.6-172.5$ & $94.7-217.7$ & $93.3-212.6$ \\
\hline Tau & 34.8-309 & $34.9-266$ & $30.3-223$ & \multicolumn{3}{|c|}{$30-150$} & & & & & & & & & \\
\hline Thr & $41.7-252$ & $51-167$ & 58.3-206 & \multicolumn{2}{|c|}{ 58-292 } & $78-197$ & $81.3-235.5$ & $74.0-238.6$ & $62.2-192.2$ & $73.3-183.5$ & $87.9-153.5$ & $79-233.2$ & $46.7-164.2$ & $74.5-211.7$ & $53.4-195.3$ \\
\hline Tyr & $24-154$ & $27.3-92.1$ & 34-101 & $41-206$ & 39 & & $38.3-116.9$ & $31.6-90.9$ & $40.5-107.2$ & $43.2-81.8$ & $55.4-98.0$ & $45.4-136.9$ & $37.9-104.9$ & $45.2-113.5$ & $52.3-125.9$ \\
\hline Val & 72.6-277 & $94.8-261$ & $99.2-329$ & \multicolumn{3}{|c|}{$102-294$} & $134.3-368.1$ & $118.3-312.0$ & $156.4-282.5$ & $155.2-272.2$ & 189.6-298.4 & $107.7-353.3$ & $140-360.3$ & $115.8-376.3$ & $152.1-362$ \\
\hline
\end{tabular}

Table 5: Amino acids-age-related reference values in plasma 


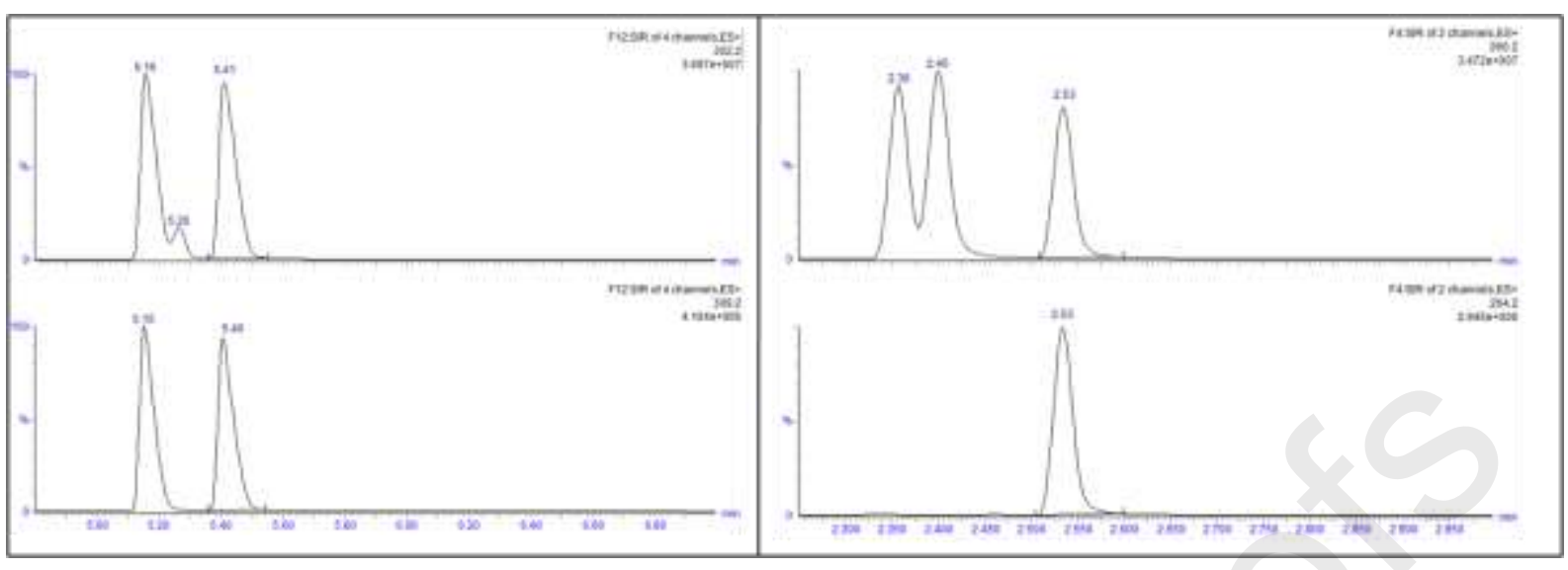

Figure 1: Chromatograms obtained by SIR (Single Ion Reaction) analysis targeted on 260.2, 264.2, 302.2 , and 309.2 uma. Isoleucine, alloisoleucine and leucine are detected respectively at 5.16, 5.26 and 5.41 minutes on channel $302.2 .{ }^{13} \mathrm{C}_{3},{ }^{15} \mathrm{~N}$, isoleucine and ${ }^{13} \mathrm{C}_{3},{ }^{15} \mathrm{~N}$, leucine (internal standards) are detected respectively at 5.15 and 5.40 minutes on channel 309.2. Sarcosine, beta-alanine and alanine are detected respectively at $2.36,2.40$ and 2.53 minutes on channel $260.2 .{ }^{13} \mathrm{C}_{3},{ }^{15} \mathrm{~N}$, alanine (internal standard) is detected at 2.53 minutes on channel 264.2 . 


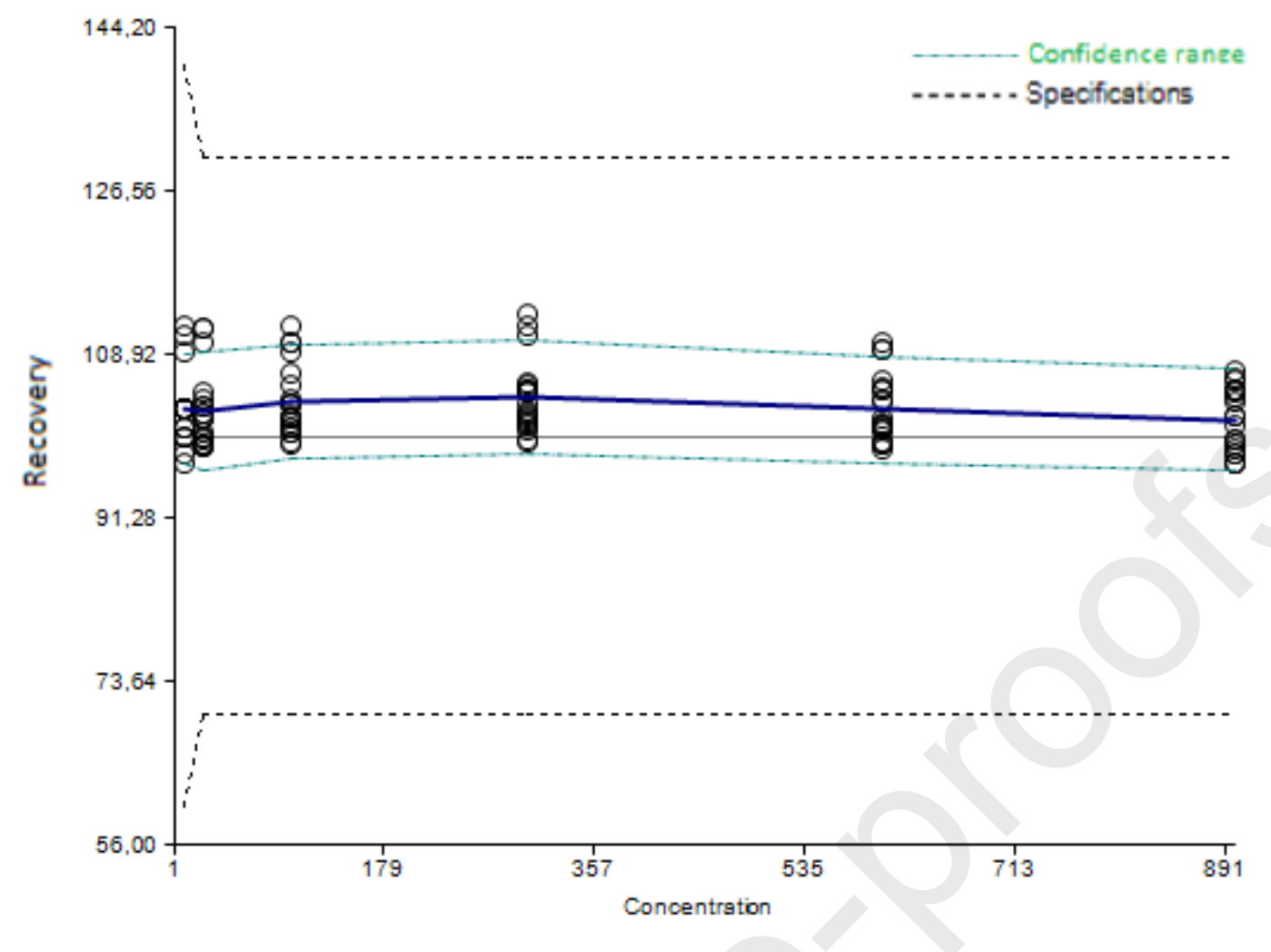

Figure 2: Example of the $\beta$-expectation tolerance interval of an AA (i.e. isoleucine). Isoleucine was analysed by UPLC-MS between $10 \mu \mathrm{mol} / \mathrm{L}$ and $900 \mu \mathrm{mol} / \mathrm{L}$. Black and continuous line represents the target and black discontinuous line the range of acceptation. Each circle represents a measurement, the blue line is the mean of each measurement and the green dotted line is the $\beta$-expectation tolerance interval. The $\beta$-expectation tolerance interval is included in specifications (black dotted line). The measured mean bias was $3.63 \%$ with an inter-days precision of $4.44 \%$. $\beta$-expectation tolerance interval of all AA are present in supplemental data. 

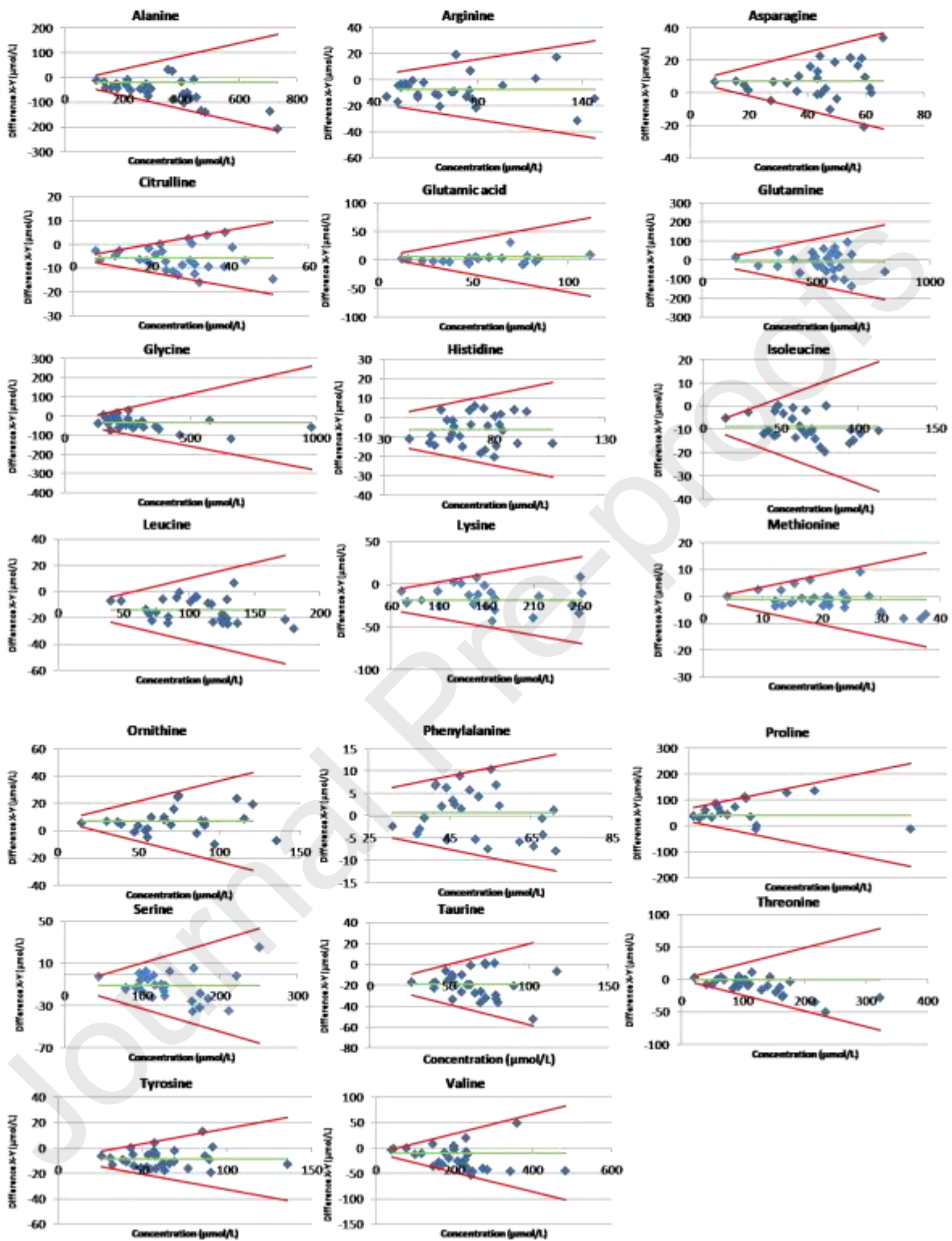

Figure 3: Bland and Altman comparison between LC-MS (method X) results and IEC method (method $Y)$ results obtained on 20 plasma samples. Red lines represent the acceptance range, based on RICOS uncertainty recommendations 

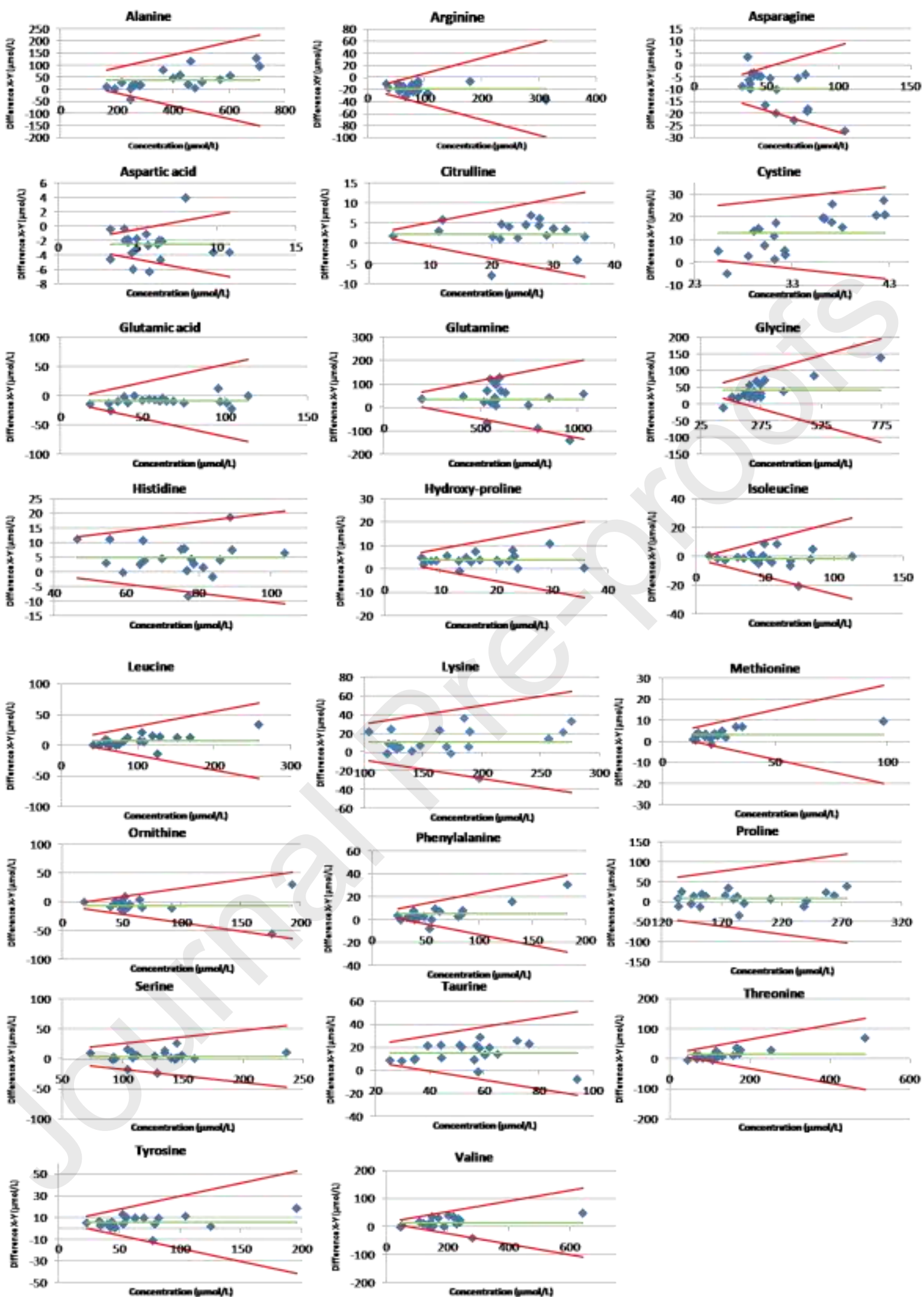

40
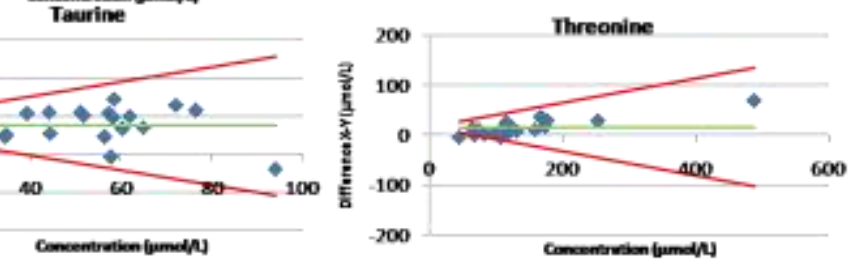

Figure 4: Bland and Altman comparison between LC-MS (method $X$ ) results and Q-Orbitrap method (method $Y$ ) results obtained on 20 plasma samples. Red lines represent the acceptance range, based on RICOS uncertainty recommendations 

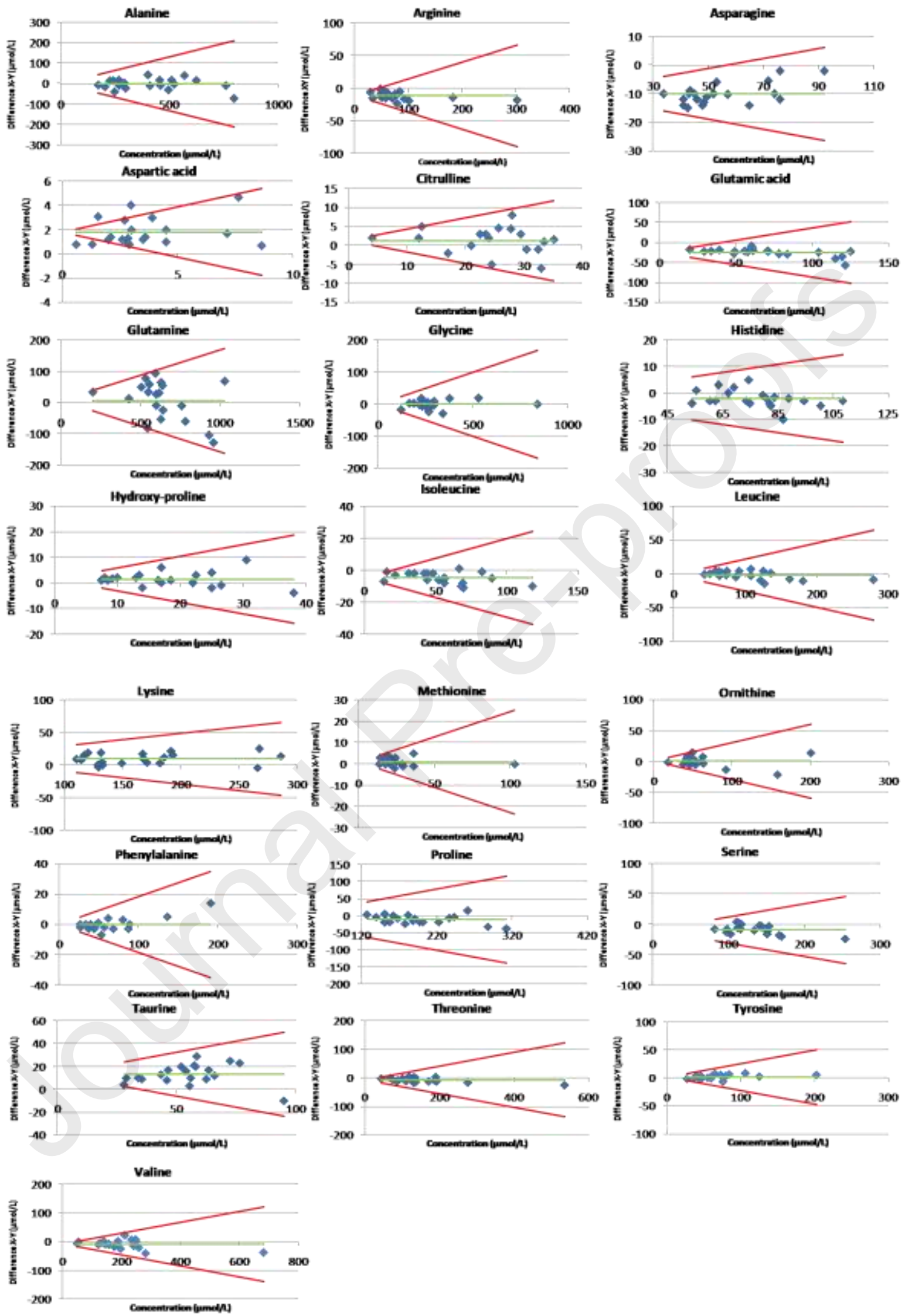

Figure 5: Bland and Altman comparison between LC-MS (method $X$ ) results and triple quadrupole method (method $Y$ ) results obtained on 20 plasma samples. Red lines represent the acceptance range, based on RICOS uncertainty recommendations 